\title{
Heart rate response of the intertidal prawn Palaemon elegans to simulated and in situ environmental changes
}

\author{
S. Morris* and A. C. Taylor \\ Department of Zoology, University of Glasgow, Glasgow G12 8QQ, Scotland, United Kingdom
}

\begin{abstract}
The response of the intertidal prawn Palaemon elegans to changes in environmental temperature was investigated in intermoult individuals weighing between 0.90 and $1.10 \mathrm{~g}$. Laboratory simulation experiments (temperature range 5 to $25^{\circ} \mathrm{C}$ ) gave $Q_{10}$ values for heart rate significantly less than 2. This is considered to be indicative of a degree of temperature independence in this species. At the acclimation temperature, the heart beat of Palaemon elegans frequently exhibited periods of cardiac arrest (pauses) not apparent if the prawn were in any way disturbed. The validity of extrapolating from these results to the natural habitat was tested by monitoring in-situ heart rates simultaneously with temperature and oxygen tension of the rock pool water from March to September 1982 using a purpose-built, microprocessor-based data logger. Environmental temperature during this period ranged from 6 to $25^{\circ} \mathrm{C}$ (annual range of -1 to $25^{\circ} \mathrm{C}$ ). Field measurements made under conditions of naturally varying oxygen tension indicate a mean $Q_{10}$ value greater than 2 and significantly different from the values obtained over the same temperature range in the laboratory. Environmental oxygen tension would appear to influence heart rate to a very much smaller extent than temperature. The study concludes that effects other than those produced by the physico-chemical environment of the pools result in $P$. elegans having a higher level of activity than is exhibited in the laboratory under a similar temperature regime. The contribution of behavioural demands to the net physiological response, apparently suppressing beneficial adaptations to a thermally variable environment, are assessed from field recordings. It is suggested that similar techniques should be used to validate data from other simulation experiments.
\end{abstract}

\section{INTRODUCTION}

Temperature and oxygen tension $\left(\mathrm{Po}_{2}\right)$ (together with $\mathrm{pH}$ ) have been identified as the 2 physical factors showing the greatest variation in temperate intertidal rock pools (Truchot and Duhamel-Jouve, 1980; Morris and Taylor, 1983). These factors are therefore likely to have the greatest effect on the physiology of the animals inhabiting these pools. The physiological importance of these factors in the marine environment has been discussed by several authors, e.g. Kinne (1964, 1970), Precht (1973), Prosser (1973), Newell (1979), Newell and Branch (1980). The prawn Palaemon elegans (Rathke) is a common inhabitant of intertidal rock pools in temperate regions. It occurs in pools high on the shore throughout the year (Morris, 1983) and has

\footnotetext{
- Present address: Institut für Zoologie TV, Universität Düsseldorf, D-4000 Düsseldorf, Federal Republic of Germany
}

had to become adapted to the extreme fluctuations in environmental conditions which characterize this habitat. The especially demanding nature of this habitat could be expected to have resulted in specific adaptations by the pool inhabitants.

As part of a wider study of the physiological adaptations of Palaemon elegans (Morris, 1983; Bridges et al. 1984, Morris et al, 1984, Morris and Taylor, in prep.), this study considers the response of $p$, elegans to environmental temperature changes in both laboratory simulations and as they occur in the natural habitat: Despite the increased interest in the physiological responses of marine animals there have been relatively few attempts to monitor these responses in the field and investigations of physiological adaptation have been largely restricted to simulation studies (see review by Davenport, 1982). One notable exception is the use of biotelemetry techniques in studies of marine and freshwater fish (reviewed by Stasko and Pincock, 
1977 and by Priede, 1983). Similar techniques have been applied in one study of the heart rate of unrestrained crabs in their natural habitat (Bottoms and Marlow, 1979), although this study was restricted to species large enough to carry the transmitter.

The necessity of studying unrestrained animals in the field is now widely recognised. Inexpensive microprocessor technology has given new impetus to such investigations. One of the earliest attempts at measuring physiological changes in marine animals in the field was that of Trueman (1967) who used a mobile laboratory for studying bivalve molluscs. In later studies this was subsequently refined (Truemann et. al., 1973) but Coleman (1974) points out that until this time, the few field studies carried out had been conducted on molluscs and barnacles, essentially sedentary animals. Progress in improving in situ monitoring techniques has been more rapid in studies of another group of sedentary animals, the corals. A progression from in situ chart recordings (Svoboda, 1978) to the use of commercial data logging systems (Porter, 1980) has culminated in the use of purpose-built, programmable, microprocessor-based data aquisition systems (Lui and Davies, 1982, Pearson et al, 1984). A semi-programmable system was first used to study errant species by Aldrich (1979) who examined the respiratory responses of Carcinus maenas within submerged respirometers. The study reported here represents the first application of data logging systems to the study of small, mobile animals in their natural habitat. This study, as well as demonstrating the application of new technology, also allows the data obtained from controlled laboratory investigations to be assessed with respect to the physiological responses recorded in the field.

\section{MATERIALS AND METHODS}

\section{Laboratory investigations}

Palaemon elegans weighing between 0.90 and $1.10 \mathrm{~g}$ were collected from intertidal rock pools on the Isle of Cumbrae, Firth of Clyde, Scotland. The experimental prawns were maintained in large aquaria (451) supplied by a recirculating seawater system in which the water temperature was maintained at $10^{\circ} \mathrm{C} \pm 1 \mathrm{C}^{\circ}$ and at a salinity of $32 \%$. The aquaria contained stones taken from the shore, under which the prawns could retreat, to help to reduce cannibalism sometimes observed with high stocking levels. Prawns were maintained under a $12 / 12$ light-dark regime and fed weekly on fresh mussels, Mytilus edulis, until $2 \mathrm{wk}$ prior to experiments. Only intermoult individuals were used in these experiments, the stock being checked daily and the recently moulted prawns isolated for 1 wk. The only exception to these procedures was the use of freshly collected prawns for investigations of endogenous heart-beat rhythms.

Recordings of the heart rate of Palaemon elegans were made using a modification of the impedance technique used by Spaargaren (1973) and by Dyer and Uglow (1977). A single silver electrode (diam = $0.05 \mathrm{~mm}$, Clark Electromedical, Reading, England) was implanted in the pericardium of the prawn via a small hole drilled in the carapace immediately dorsal to the heart using a fine hypodermic needle $(26 \mathrm{~g})$. The underlying hypodermis and pericardial membrane were penetrated by the electrode insertion. The electrode was fixed in place using quick setting cyanoacrylate adhesive, the setting time of which was reduced to less than $3 \mathrm{~s}$ by using methyl methacrylate as an accelerator.

The silver electrode had been previously soldered to polyurethane coated copper wire (diam $=0.125 \mathrm{~mm}$, R. S. Components Ltd., London) which was extremely light and flexible and offered minimal resistance to the prawn's movement. All submerged connections were insulated using a thin coating of adhesive. A second external electrode was wound around the copper lead of the first, indwelling electrode, immediately above the point of entry into the carapace. This arrangement maintained the geometry of the electrodes and was thus insensitive to movement of prawn. Signal noise was further reduced by making the external electrode approximately 10 times larger than the internal electrode. The prepared specimen was then installed in a 251 aquarium tank and allowed to acclimatise to experimental conditions, with the exception of those prawns used in investigations of endogenous rhythms. For the latter studies, freshly collected individuals were prepared and recordings initiated within $4 \mathrm{~h}$. Experimental animals were kept either under a $12 / 12$ light:dark cycle or in continuous darkness in the aquarium and recordings made throughout the next 2 to $5 \mathrm{~d}$. In all laboratory determinations oxygen tension of the water was kept at normoxic levels by an air line secured in a corner of each tank by a perforated partition.

Changes in impedance signal were recorded using a George Washington impedance pneumograph and pen recorder. Heart rate recording commenced immediately after the insertion of the electrode to determine the maximum heart rate, and then at $15 \mathrm{~min}$ intervals over a period of 4 to $8 \mathrm{~h}$ to establish when a quiescent rate was achieved, before the experiment was initiated. The acute response of heart rate to temperature change with the range 5 to $25^{\circ} \mathrm{C}$ was measured in prawns $(n>35)$ acclimated to $10^{\circ} \mathrm{C}$ as previously described. The $Q_{10}$ value for the appropriate temperature change was then calculated, as a measure of 
temperature sensitivity, from the steady state recordings made before and after the acute response to the change in water temperature.

\section{Field recordings}

Simultaneous recordings of the heart rate of Palaemon elegans and of the temperature and $\mathrm{PO}_{2}$ of the water were carried out in rock pools in the intertidal zone of Great Cumbrae Island. The pools chosen were inhabited by $P$, elegans, situated at 2.4 and $2.9 \mathrm{~m}$ above chart datum, and just covered by neap tides. Recordings were made using a microprocessor-based data logging system (Fig. 1), This portable system was developed as a modification of the system employed by Pearson et al. (1984) and powered by two 15 ampere 12 $\mathrm{V}$ accumulators capable of supplying power to the system for up to $5 \mathrm{~d}$.

\section{Sensors: physical}

Temperature was recorded using a temperature sensitive integrated circuit (R. S. Components, London) embedded in a water-proof perspex tube (diam $=0.5$ $\mathrm{cm}$ ). Calibration in the range 0 to $30^{\circ} \mathrm{C}$ gave a sensitivity $>0.01 \mathrm{C}$. Measurements of oxygen tension in the pools were made using a microcathode oxygen electrode (Radiometer E 5046, Copenhagen, Denmark). This electrode has a low rate of oxygen consumption; therefore stirring of the water in order to avoid local $\mathrm{Po}_{2}$ gradients in the still water of pools was not necessary (Morris and Taylor, 1983). The electrode was calibrated in air immediately before immersion. Calibration in the range 0 to 500 Torr gave a sensitivity $>0.5$ Torr. The electrode was fitted with a perforated plastic guard to protect the membrane but did not restrict the movement of water across the membrane of the electrode. The electrode was connected to the polarising source and to the data logger by a $30 \mathrm{~m}$ coaxial cable.

\section{Heart rate}

Heart rate was monitored using the same arrangement of electrodes as described for laboratory determinations. Electrodes were connected to high frequency impedance monitors by $30 \mathrm{~m}$ lengths of 1 amp cable, the connectors being insulated and immobilised against the rock surface using modelling clay.

All prawns were collected in the vicinity of the monitoring site and electrode implantation performed in the field. Prawns were returned to pools within 45 min of being captured and recordings were usually

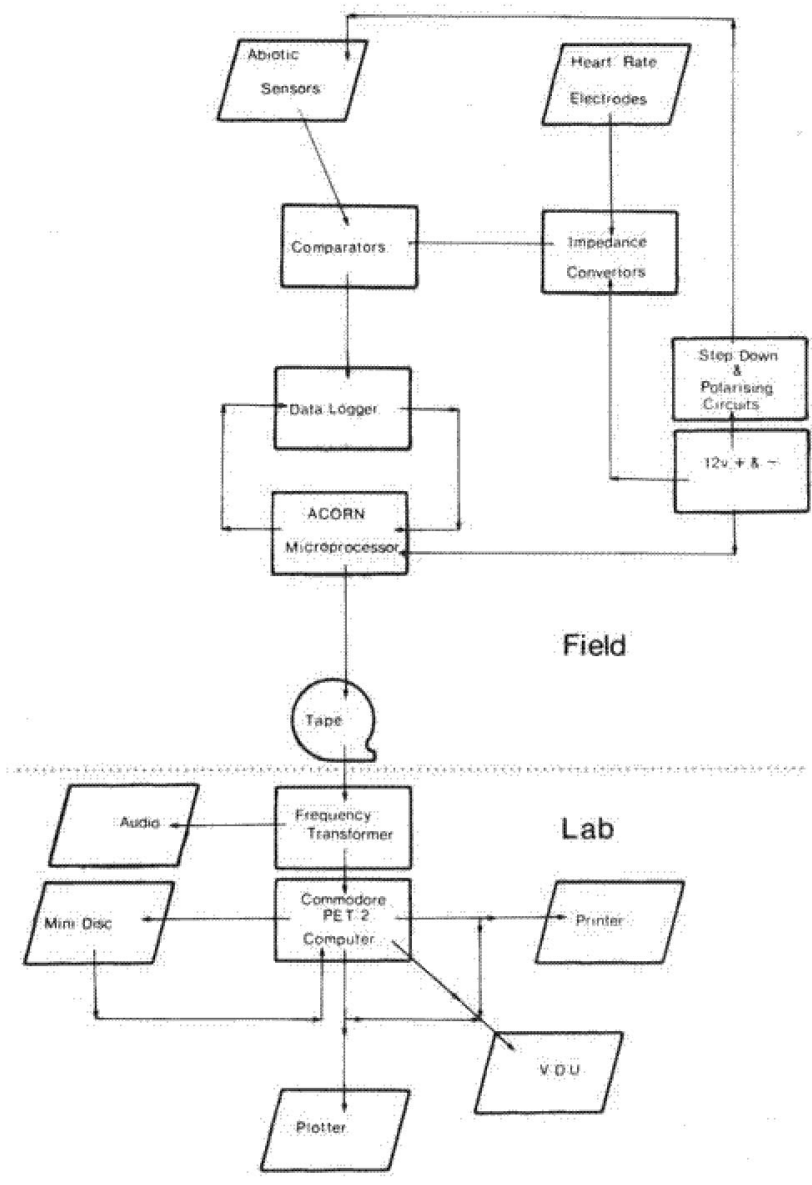

Fig. 1. Diagram of monitoring system used for collecting data on heart rate and physico-chemical parameters in rock pools

initiated within $2 \mathrm{~h}$ of this time Recordings were generally made for periods of 12 to $24 \mathrm{~h}$, but their actual duration was dependent on the life-time of the polyurethane coating on the copper electrode leads.

Impedance frequency/voltage convertors were specifically designed to operate on the same $12 \mathrm{~V}$ power source as the data logger. Heart beats detected by each of the 3 impedance circuits were displayed, not by the usual pen trace but on serial LED's (light emitting diodes) recording the voltage change associated with each heart beat. The impedance signal was converted to a digital form by a threshold voltage detector with built in hysteresis. This ensured that only true heart beats were recorded and that any signal noise was ignored.

\section{Data recording and processing}

The input signal from each sensor was fed into a separate comparator circuit identical to that used by Pearson et al (1984). The signal to each of these circuits was amplified and then compared with the output 
voltage of a counter driven D/A convertor. The central processing unit (CPU) was an Acorn microcomputer utilising a 6502 microprocessor. The collected data were stored utilising $1.5 \mathrm{~K}$ RAM (Random Access Memory) and the monitor program in $1.5 \mathrm{~K}$ of a $2 \mathrm{~K}$ EPROM (Eraseable-Programmable Read-Only Memory). The machine code microcomputer also had a hexadecimal keypad for program entry and control. This allowed both the current readings of the comparator circuits and the recorded values to be displayed for the purposes of calibration and initial evaluation in the field.

For this study, the microprocessor unit was programmed so that each of the recording channels was monitored three times at $5 \mathrm{~min}$ intervals. Each of the 3 monitoring periods for the heart rate consisted of a $30 \mathrm{~s}$ counting period. The data from each channel were then stored and the system powered down to economize on battery life, with the exception of the data storage memory and the low power quartz crystal timer that determined when the system was to be powered up. After an elapsed time of 100 min the data stored in the memory were transferred to an ordinary ferromagnetic cassette tape to provide a permanent record.

Recordings were made over 12 and $24 \mathrm{~h}$ periods during both diurnal and nocturnal tidal cycles from March to September 1982. The permanent record on tape was then returned to the laboratory for analysis. Playback via a cassette tape interface into a Commodore PET 2 microcomputer allowed the data to be manipulated using BASIC. The computer was programmed to accept the calibration figures for $\mathrm{Po}_{2}$ and temperature to enable the actual values to be calculated from the data recorded by the logger. The decoded values were then stored on mini-disks permitting access to data at a later date. The recorded data could then be obtained as a chronological listing or could be plotted automatically using a graph plotter (Watanabe DIGI-PLOT).

\section{RESULTS}

\section{Laboratory investigations}

Recordings of heart rate made in the laboratory at intervals of 5 to $15 \mathrm{~min}$ immediately following insertion of the pericardial electrode showed an initial elevated rate followed by a rapid recovery of the quiescent rate within 3 to $4 \mathrm{~h}$ (Fig. 2). The pattern of heart beat in quiescent prawns maintained at $10^{\circ} \mathrm{C}$ was normally very regular but occasionally brief periods of cardiac arrest were recorded (Fig. 3). The duration of these cardiac pauses was usually less than $5 \mathrm{~s}$ but the

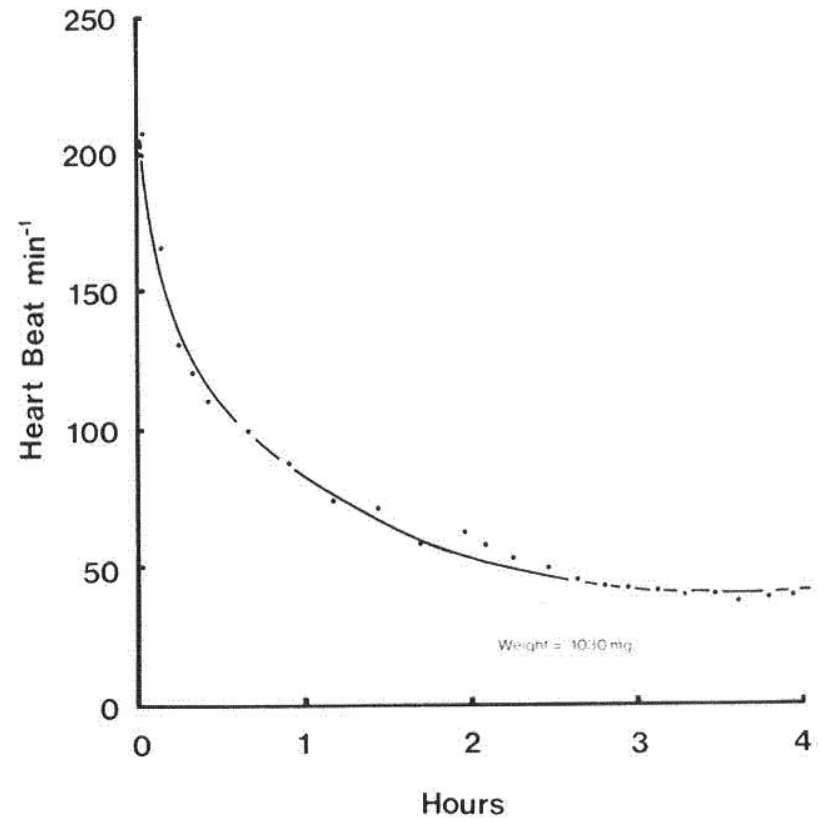

Fig. 2. Palaemon elegans. Change in heart rate during a $4 \mathrm{~h}$ period immediately following electrode insertion in an individual at $10^{\circ} \mathrm{C}$

a

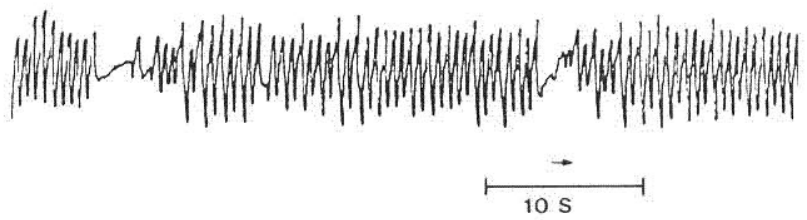

b

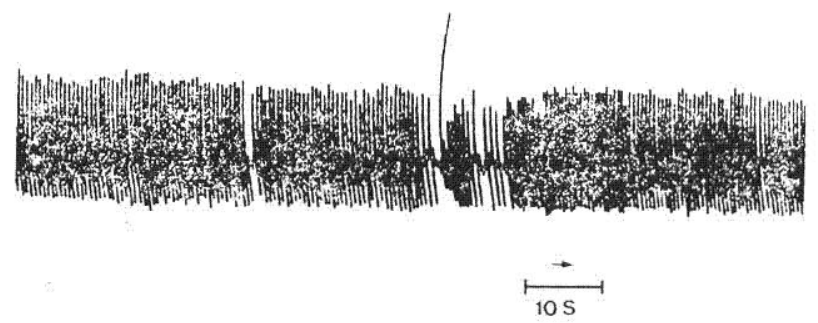

Fig. 3. Palaemon elegans. Heart rate recordings made using impedance technique on the same individual as in Fig. 2 at $10{ }^{\circ} \mathrm{C}$. The 2 recordings ( $\mathrm{a}$ and $\mathrm{b}$ ) were made on 2 different occasions under normoxic conditions; they demonstrate the occurrence of brief periods of cardiac arrest in this species

frequency of pausing varied considerably between individuals and with time. This pattern of cardiac activity was disrupted at the slightest disturbance of the prawn and resulted in the resumption of continuous beating. For this reason, extensive records of activity were not made although it was observed that the 
prawns moved freely around the aquarium but did not spontaneously engage in swimming.

Circulatory pauses in Palaemon elegans may occur as simple cessation of beating followed by the reestablishment of normal rates when cardiac activity is recommenced (Fig. 3a). Occasionally, however, such pauses were succeeded by periods of erratic and often high frequency beating before the normal resting rate was resumed ( $\mathrm{Fig}$. 3b). There was no correlation between the 2 types of pausing and the state of the prawn since both often occurred in single individuals soon after a resting heart rate had been established. Quantitative analysis of the amplitude of impedance records was not attempted because other authors have shown that the amplitude of impedance records may not be directly proportional to the amplitude of contraction of the heart (Depledge, 1978). Pausing represented the only irregularity in the heart rate of undisturbed prawns and the long-term record of any individual characteristically deviated from the mean rate by less than $12 \%$.

\section{Effects of temperature on the rate of heart beat}

The effect of temperature change on heart rate was assessed only for Palaemon elegans weighing between 0.90 and $1.10 \mathrm{~g}$ since this represented the smallest size which could be used to consistently obtain successful electrode implantations. Thus it was not possible to obtain a completely accurate estimate of the relation between heart rate and body weight. Repeated measurements of the response to acute temperature change were not carried out on individual prawns since a 'thermal history' could have affected the heart rate response to subsequent temperature changes. For example, the acute response of heart rate to a temperature change from 10 to $20^{\circ} \mathrm{C}$ was large but demon-
Table 1. Palaemon elegans. Heart rate $\mathrm{Q}_{10}$ values for individuals acclimated to $10^{\circ} \mathrm{C}$ in the laboratory

\begin{tabular}{|cc|}
\hline Temperature range $\left({ }^{\circ} \mathrm{C}\right)$ & $Q_{10}$ \\
\hline $5-10$ & 1.40 \\
$10-15$ & 1.83 \\
$15-20$ & 1.19 \\
$20-25$ & 1.35 \\
\hline
\end{tabular}

strated the apparently rapid recovery $(4 \mathrm{~h})$ of the resting state (Fig. 4). This recovery rate was similar to the situation previously described for post-operative individuals. A subsequent change from 20 to $25^{\circ} \mathrm{C}$ produced a further elevation in rate. This was, however, a much slower response than that exhibited when the temperature was raised directly from 10 to $25^{\circ} \mathrm{C}$. This delayed response to subsequent temperature changes was observed in a large number of experimental animals $(n>30)$; the extent of the delay was, however, extremely variable between individuals. The period of the delay could not be correlated with the initial temperature change or with the size of the subsequent temperature step. Because it became apparent that it was important to use each prawn only once for these experiments, the $Q_{10}$ values were calulated from data from a number individuals of similar weight (Table 1). The prawns used in these determinations exhibited very similar rates of heart beat, giving a resting rate at $10^{\circ} \mathrm{C}$ of $96.7 \pm 9.1$ beats $\mathrm{min}^{-1}$.

\section{In situ recordings of heart rate, water temperature and $\mathrm{Po}_{2}$}

During this study it was possible to carry out a number of recordings of the variation in the temperature and $\mathrm{Po}_{2}$ of rock pool water and heart rate of unrestrained Palaemon elegans, using the data logger
Fig.4. Palaemon elegans. Response of heart rate of 2 individuals to sudden changes in temperature. The first individual (solid line) was initially exposed to a temperature of $20^{\circ} \mathrm{C}$ for $4 \mathrm{~h}$, at the end of which it was exposed to a further increase in temperature to $25^{\circ} \mathrm{C}$. The second individual (broken line) was exposed to a rapid change in temperature for 10 to $25^{\circ} \mathrm{C}$ without preliminary exposure to $20^{\circ} \mathrm{C}$

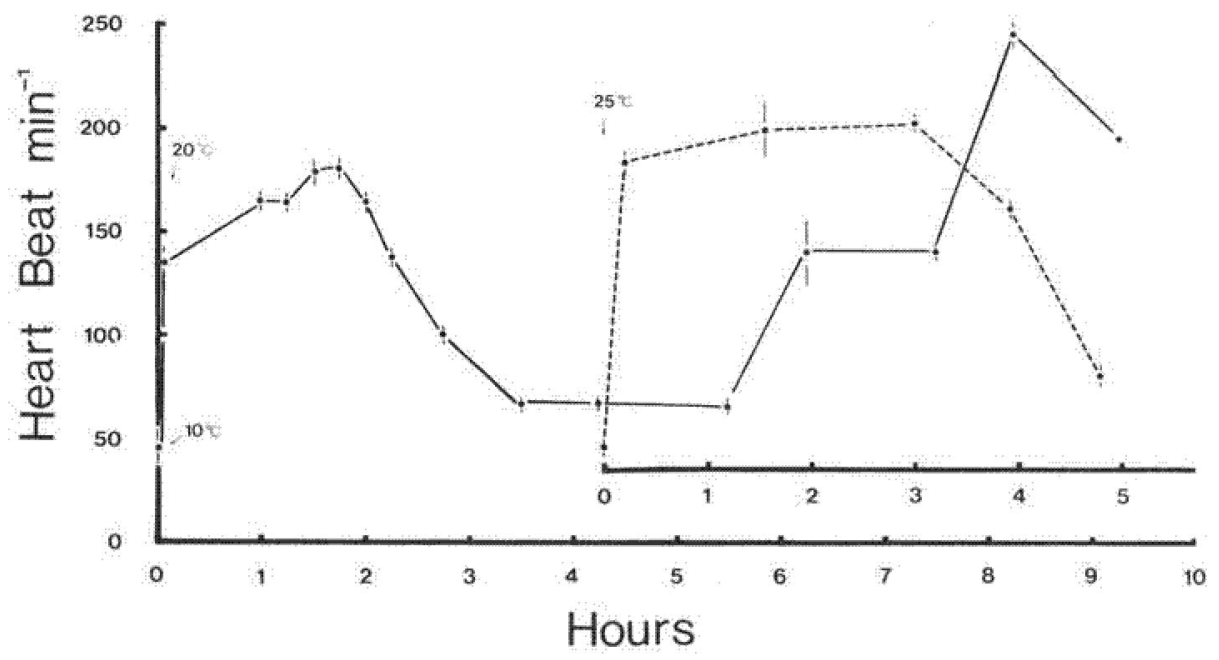


described above. The normal relation between changes in water temperature and $\mathrm{Po}_{2}$ described previously (Morris and Taylor, 1983) was also recorded in this study. The typical annual temperature range for these pools was -1 to $25^{\circ} \mathrm{C}$ although after March the temperature rarely fell below $6^{\circ} \mathrm{C}$. The lower temperature was dictated by that of the water in the Clyde Estuary.

Heart rate in Palaemon elegans was extremely variable throughout a diurnal or tidal cycle (Fig. 5). Individuals characteristically exhibited a daily range of approximately 50 beats $\mathrm{min}^{-1}$, e.g. 50 to 100 beats $\mathrm{min}^{-1}$. Maximum rates often approached 200 beats $\mathrm{min}^{-1}$, but periods of cardiac arrest (pausing) were not observed during these field measurements. On no occasion $(\mathrm{n}=26)$ was the initial rate the maximum rate recorded and thus indicated that the prawns recovered rapidly from electrode insertion and may also be indicative of a high level of routine activity in this species under field conditions Actual observations of animal activity in the pools was not possible without removing or disturbing major areas of algae and thus significantly disrupting the environment. Similarly, diver observations at high tide always induced the animals to swim and were thus of little value.

Records of temperature (Fig. 5) show the characteristic pattern whereby the water temperature rises during the daylight ebb tide to that of the air but during a nocturnal ebb the water temperature declines. On those occasions, however, when the air temperature differed little from that of the sea, temperature changes in the rock pool were observed to be slight and far more gradual. These relatively stable water temperatures are still accompanied by the normal diumal oscillation in pool oxygen tension (Fig. 6). These relatively slow, oscillatory changes are interrupted by the incoming tide which can on occasion produce rapid fluctuations in water temperature.

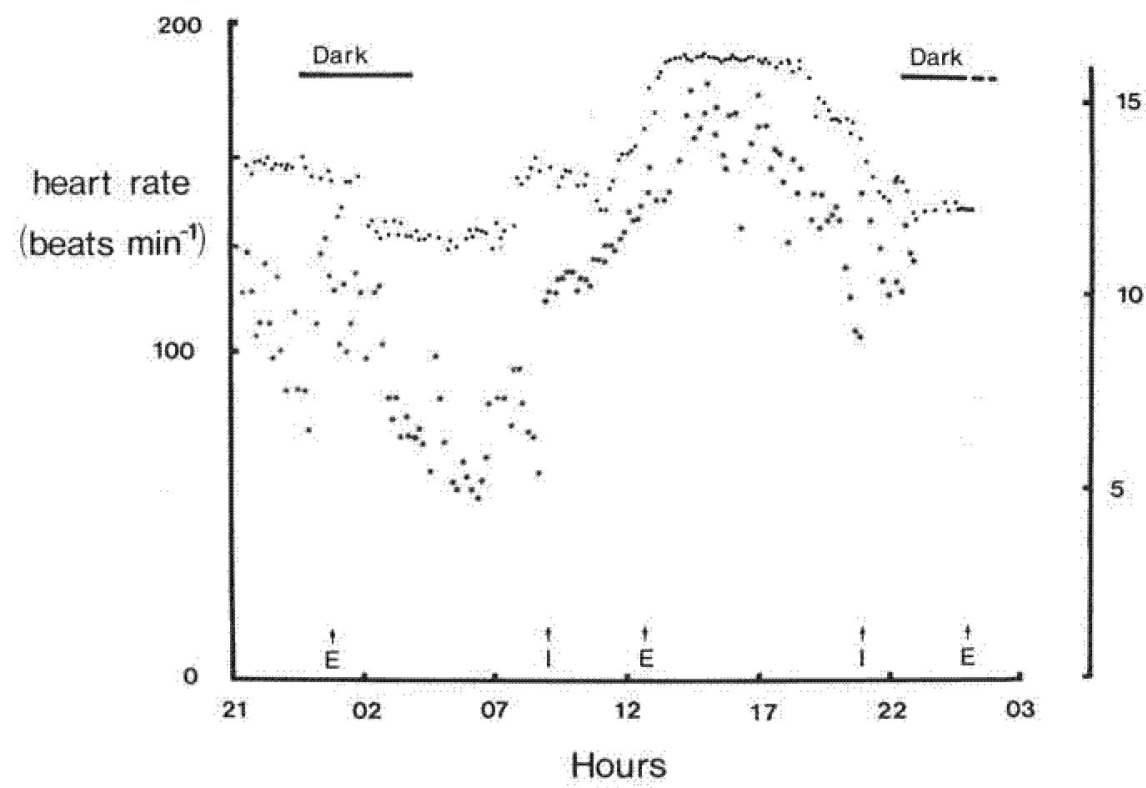

Fig. 5. Palaemon elegans. Continuous recording of water temperature ( $\bullet$ ) of heart rate (") over $24 \mathrm{~h}$ in a high-level rock pool during spring tides.

(I: immersion, El emersion)

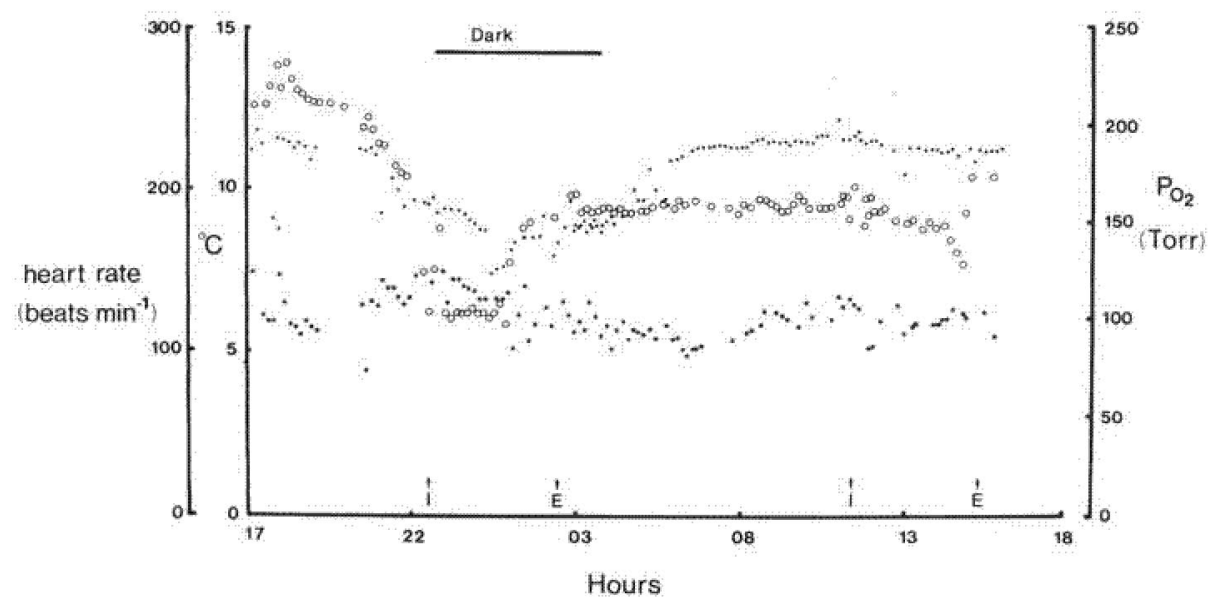

Fig. 6. Palaemon elegans. Continuous recordings of heart rate (*), temperature $(\cdot)$ and $\mathrm{PO}_{2}(\mathrm{o})$ of the water in an intertidal rock pool during a $24 \mathrm{~h}$ period. (I: immersion, $\mathrm{E}$ : emersion) 
Changes in water temperature were recorded simultaneously with heart rate of Palaemon elegans in the pool (Fig. 5). Increases in temperature of more than 1 or $2 \mathrm{C}^{\circ}$ invariably produced an increase in heart rate with calculated $Q_{10}$ values of $2.24 \pm 0.27(n=14)$. Rate of heart beating at any one time during the recording period was more variable during periods of relatively stable temperatures. Large temperature changes reduced the variability of heart rate over a short period even though overall the rate change followed that of temperature change, with little or no delay in the response.

\section{DISCUSSION}

\section{Cardiac activity in quiescent prawns}

Heart rate data for Palaemon elegans were obtained from a narrow size range of prawns and thus give little information as to size dependency, although larger individuals usually exhibited slower rates. This is in agreement with a number of previous studies on crustaceans and other invertebrates (e.g. DeFur and Mangum, 1979).

The pattern of heart beat in Palaemon elegans in normoxic water strongly resembles that of $P$, serratus (Spaargaren, 1973), which shows similar short duration pausing. Such periods of cardiac arrest and extreme bradycardia are quite common in decapods (McMahon and Wilkens, 1972, Bridges, 1979, Schembri, 1979; McDonald et al, 1980, Burnett and Bridges, 1981; Bradford and Taylor, 1982; Taylor, 1984). The functional significance of this pausing, observed in quiescent individuals, is not clear. Present opinion (Bottoms, 1977. McMahon and Wilkens, 1977, McDonald et al, 1980, Bradford and Taylor, 1982; Taylor 1984) is that pausing may enable the animal to achieve a saving in metabolic energy expenditure. In reptant decapods, pausing would appear to be of longer duration but to occur less frequently than in Palaemon elegans. Circulatory pausing in Cancer magister has been shown, however, to be temperature dependent, higher temperatures reducing the frequency of pausing (McMahon et al., 1978). This may reflect increased metabolic rate at higher temperatures.

Measurements of environmental parameters in intertidal rock pools have shown that temperature is one of the most variable physico-chemical factors and undergoes large, often rapid changes (e.g. Truchot and Duhamel-Jouve, 1980; Morris and Taylor, 1983). Poikilothermic animals need not have body temperatures equal to that of the environment (Stevens and Fry, 1970) but the absence of any effective homeostatic mechanism results in a strong correlation between the two. A large proportion of metabolic reactions show
$Q_{10}$ values between 2 and 2.5 within the environmental temperature range. Somewhat lower values for $Q_{10}$ of between 1 and 2 may be exhibited, however, over a limited range within this environmental temperature range (see review of Newell, 1979). This would appear to be the case in Palaemon elegans since $Q_{10}$ values for the heart rate of less than 2 were obtained in laboratory experiments.

This temperature independence of $Q_{10}$ is a feature of quiescent animals and is not shown by disturbed individuals. Many examples of this phenomenon are known among marine invertebrates, e.g. in Littorina littorea and in Mytilus edulis (Newell and Pye, 1970a, b), in Actinia equina, Cardium edule and Nephrops norvegicus (Newell and Northcroft, 1967) and in Callinectes sapidus (Burton et al, 1980). Partial temperature independence, similar to that in $P_{\text {. elegans, has }}$ been found in Patella vulgata (Davies, 1966, 1967), in the ostracod Hirschmania viridis (Hagerman, 1969) and in some sea urchins (Ulbricht and Pritchard, 1972). Newell (1979) proposed a correlation between the possession of temperature independent metabolism and the habitat of the animal since animals from thermally stable habitats need be adapted to only a very narrow temperature range. This is supported both by the results of this study and by the study of Burggren and McMahon (1981) who found $Q_{10}$ values of 1.4 to 1.6 for intertidal crabs but values of 2.1 to 2.4 and 2.6 to 2.7 for subtidal and supratidal species respectively.

This regulation of metabolic rate during temperature change should be considered with respect to behaviour, Palaemon elegans like Carcinus maenas (Arudpragasm and Naylor, 1964), is most active during the part of the tidal cycle in which temperature is most variable (emersion period) with a peak of activity immediately after the tide has receded (Rodriguez, 1970). This activity is not induced by cyclical changes in environmental $\mathrm{PO}_{2}$ since stable heart rates were frequently recorded when the $\mathrm{Po}_{2}$ varied rapidly. Additionally, the lower $\mathrm{Q}_{10}$ values recorded in the laboratory demonstrate that temperature fluctuations do not directly stimulate activity. Such activity would tend to obscure any temperature independence that is a feature of quiescent animals and it is possible that without the immobility imposed by aerial exposure, $P$. elegans rarely achieves extremely low metabolic rates. Hochachka and Somero (1973) consider the effects of activity on compensatory mechanisms for temperature fluctuations and conclude that activity is likely to induce increases in substrate concentration and that various tissues from ectothermic species only exhibit temperature independence when substrate concentrations are at resting physiological levels, Consequently, thermal compensation is most apparent when substrate concentrations are low in quiescent animals. 
Palaemon elegans is an active carnivore and scavenger and it is therefore likely that this species might exhibit very low metabolic rates only infrequently. A behavioural adaptation whereby $P$, elegans becomes 'totally' quiescent would be required if the prawns were to take advantage of the low $Q_{10}$ values exhibited by quiescent animals in the laboratory. Whilst such a hypothesis may be tested in the laboratory, and the possession of thermoregulatory mechanisms has been demonstrated in $P$. elegans, such experiments provide only limited information as to the actual response of the animal in the field.

\section{Field studies using the data logger}

These studies, representing the initial use of this microprocessor system, demonstrated several advantages over previous methods, the most important being the production of continuous, concurrent records for several variables. A further advantage is that the use of a microcomputer to decode the very large volume of data on tape also greatly facilitates data analysis.

One disadvantage of this monitoring system, however, is the relative insensitivity of the recording method to short-term fluctuations in heart beat. In the laboratory, quiescent prawns often showed periods of cardiac arrest (pausing) but in the field short periods of cardiac arrest would be recorded only as reductions in the measured rate, appearing as a variable heart rate similar to that shown in Fig. 5. However, because circulatory pauses are shown only by quiescent Palaemon elegans under relatively constant temperature conditions, it is unlikely that they occur extensively under field conditions where temperature usually varies continuously (Morris and Taylor, 1983).

Results clearly show the diurnal variation in temperature and oxygen tension, together with more rapid changes associated with immersion and emersion. As might have been predicted from laboratory results, temperature has a significant effect on Palaemon elegans heart rate in the field. The record showing relatively long periods of stable temperature but with variable $\mathrm{Po}_{2}$ (Fig. 6) indicates that this species is able to maintain its metabolism independent of a wide range of environmental oxygen tension. This observation is in agreement with other work on $P$. elegans which reports that heart rate is independent of oxygen tension in the range 20 to 500 Torr (Morris, 1983; Morris and Taylor, in prep.).

It was possible to calculate $Q_{10}$ for heart rate from the simultaneous records of temperature and heart rate. The $Q_{10}$ calculated from the field results $\left(Q_{10}=2.24 \pm\right.$ 0.27 ) was significantly different to that calculated from laboratory data $\left(\mathrm{Q}_{10}=1.78 \pm 0.26\right),(\mathrm{t}[20]=3.47,0.01$
$>\mathrm{P}>0.002$ ), within the temperature range 10 to $20^{\circ} \mathrm{C}$. The observed increase in temperature dependence of Palaemon elegans in the field in comparison with prawns in the laboratory has several implications. Firstly, that a change in temperature does not directly increase activity which would further increase metabolic rate and would lead to increased values of $Q_{10}$. Secondly, that factors which were not present or which were controlled in the laboratory occur in rock pools and increase temperature sensitivity perhaps by increasing activity. Two likely possibilities are the availability of food and interaction between individuals. Both of these factors act primarily on the behaviour of the prawn which then elicits physiological responses (i.e. increased activity), greatly reducing the efficacy of the compensatory mechanisms measured in the laboratory. The opportunity to maintain activity throughout the whole tidal cycle is not available to most intertidal species outside the pools and this is reflected by the low $Q_{10}$ values recorded by Colemann and Trueman (1971) for heart rate in Mytilus edulis under in situ conditions. This would tend to support the conclusion based on laboratory and field studies that $P$. elegans might only infrequently assume quiescent rates because rock pool species do not experience aerial exposure and enforced immobility, together with regular periods of reduced food availability.

These findings result in the rather paradoxical situation whereby Palaemon elegans exhibits both circulatory pausing and low $Q_{10}$ values in the laboratory, apparently beneficial adaptations, but does not appear to benefit extensively from these features under natural conditions. The only time at which $P$. elegans was observed to maintain the sustained immobility necessary for these features to become manifest was under extreme temperature conditions in which the regulative abilities of the prawn are considered to be inoperative. This being the case, it is difficult to determine the selective force that has promoted the evolution of these factors and what might be the routine physiological advantage. The presence of uncontrolled variables in the natural environment, whilst unavoidable, does complicate the interpretation of field data. Nevertheless, this study has demonstrated the importance of carrying out in situ studies in order to establish to what extent the laboratory determinations reflect the actual response shown by animals in their natural habitat.

Acknowledgements We thank Dr, M. D. Burns and Mr. M. P. Pearson for invaluable aid in the development of the microprocessor system and programs, as well as Director and staff of the University Marine Biological Station, Millport, This work was carried out whilst S.M. was in receipt of an S.E.R.C. Research Studentship. 


\section{LITERATURE CITED}

Aldrich, J, C, (1979). In situ recordings of oxygen consumption rhythms in Carcinus maenas. Comp. Biochem. Physiol. $64 \mathrm{~A}: 279-283$

Arudpragasm, K. D., Naylor, E. (1964). Gill ventilation volumes, oxygen consumption and respiratory rhythms in Carcinus maenas (L.). J, exp. Biol. 41: 309-321

Bottoms, A. (1977). Some aspects of the respiratory physiology of Cancer pagurus (L.) (Crustacea: Decapoda) in Scottish West Coast waters. Ph. D. thesis, University of Stirling, Scotland

Bottoms, A., Marlow, J. (1979). A new ultrasonic tag for telemetry of physiological functions from aquatic animals. Mar, Biol. 50: $127-130$

Bradford, S. M., Taylor, A. C. (1982). The respiration of Cancer pagurus under normoxic and hypoxic conditions. J. exp, Biol. $97: 273-188$.

Bridges, C. R. (1979). Adaptations of Corystes cassivelaunus

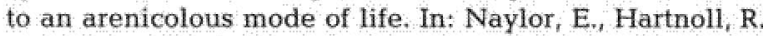
G. (ed.) Cyclic phenomena in marine plants and animals. Proceedings of 13th European Marine Biology Symposium. Pergamon Press, Oxford, p. 317-324

Bridges, C. R., Morris, S, Grieshaber, M. K. (1984). Modulation of haemocyanin oxygen affinity in the intertidal. prawn Palaemon elegans (Rathke). Resp. Physiol. (in press)

Burggren, W. W., McMahon, B, R. (1981). Oxygen uptake during environmental temperature change in hermit crags: adaptation to subtidal, intertidal and supratidal. habitats. Physiol Zool. $54,325-333$

Burnett, L. E., Bridges, C. R. (1971). The physiological properties and function of ventilatory pauses in the crab Cancer pagurus. J comp. Physiol. 145: 81-88

Burton, D. T, Richardson, L. B, Moore, C. J. (1980). Cardiac frequency compensation responses of adult blue crabs (Callinectes sapidus) exposed to moderate temperature. increases. Comp. Biochem. Physiol. 65A: 259-263

Coleman, N. (1974). The heart rate and activity of bivalve molluscs in their natural habitat. Oceanogr. mar. Biol. A. Rev. 12: $301-313$

Coleman, N., Trueman, E. R. (1971). The effect of aerial exposure on the activity of the mussels Mytilus edulis $\mathrm{L}$. and Modiolus modiolus (L.). J. exp. mar Biol. Ecol. 7 : 295-304

Davenport, J. (1982). Environmental simulation experiments on marine and estuarine animals. Adv. mar Biol. 19: 133-256

Davies, P. S. (1966). Physiological ecology of Patella I. The effect of body size and temperature on metabolic rate. J. mar. biol. Ass, U. K, 46: 647-658

Davies, P. S. (1967). Physiological ecology of Patella II. Effect of environmental acclimation on the metabolic rate. $\mathrm{J}$. mar. biol. Ass. U. K. 47: 61-74

DeFur, P. L., Mangum, C. P. (1979). The effects of environmental variables on the heart rates of invertebrates. Comp. Biochem. Physiol. 62A: 283-294

Depledge, M. H. (1978). Cardiac activity of the shore crab, Carcinus maenas (L). Comp. Biochem. Physiol. 60A: 65-67

Dyer, M. F. Uglow, R. (1977). On a technique for monitoring heart and scaphognathite activity in natantia. J. exp. mar. Biol. Ecol. 27: 117-124

Hagerman, L. (1969). Environmental factors affecting Hirschmania viridis (O. F. Muller) (Ostracoda) in shallow: brackish water Ophelia 7:79-99
Hochachka, P. W., Somero, G. N. (1973). Strategies of biochemical adaptation. W. B. Saunders, Philadelphia

Kinne, O. (1964). Adaptation to the environment. In: Dill, D. B., Adolph, E. F., Wilber, C. G. (ed) Handbook of physiology. American Physiological Society, Washington D. C., p. 669-682

Kinne, O. (1970). Temperature - invertebrates. In: Kinne, $O$. (ed.) Marine ecology, Vol. 1, Environmental factors. Wiley Interscience, London, p. 407-514

Lui, Y. S. B, Davies, P. J. (1982). A microprocessor-based underwater data aquisition system. Coral Reefs 1; 59-65

McDonald, D. G., Wood, C. M., McMahon, B. R. (1980). Ventilation and oxygen consumption in the Dungeness crab, Cancer magister. J. exp. Zool. 213: 123-136

McMahon, B. R, Sinclair, F., Hassal, C. D., DeFur, P. L., Wilkes, P. R. H. (1978). Ventilation and control of acidbase status during temperature acclimation in the crab, Cancer magister. J. comp. Physiol. 128: 109-116

McMahon, B. R., Wilkens, J. L. (1972). Simultaneous apnoea and bradycardia in the lobster Homarus americanus. Can. J. Zool, 50: 165-170.

McMahon, B. R, Wilkens, J. L. (1977). Periodic respiratory and circulatory performance in the red rock crab Cancer productus. J. exp. Zool. 202: 363-374

Morris, S. (1983). Physiological adaptations in the intertidal prawn, Palaemon elegans (Rathke). Ph. D. thesis, University of Glasgow, Scotland

Morris, S., Taylor, A. C. (1983). Diurnal and seasonal variation in physico-chemical conditions within intertidal rock pools. Estuar. coast. Shelf Sci. 17:339-355

Morris, S. Taylor, A. C. Bridges, C. R., Grieshaber, M. K. (1984). Respiratory properties of the haemolymph of the intertidal prawn, Palaemon elegans (Rathke). J, exp. Zool. (in press)

Newell, R. C. (1979), Biology of intertidal animals, 3rd ed. Marine Ecological Surveys, Faversham, Kent, England

Newell, R, C., Branch, C. M. (1980). The influence of temperature on the maintenance of metabolic energy balance in marine invertebrates. Adv. mar. Biol. 17: 329-396

Newell, R. C., Northcroft, H, R. (1967). A re-interpretation of the effect of temperature on the metabolism of certain marine invertebrates. J. Zool, Lond. 151: 277-298

Newell, R. C., Pye, V. I (1970a), Seasonal changes in the effect of temperature on the oxygen consumption of the winkle Littorina littorea (L.) and the mussel Mytilus edulis (L). Comp. Biochem. Physiol, $34,367-383$

Newell, R. C., Pye, V. I. (1970b). The influence of thermal acclimation on the relationship between oxygen consumption and temperature in Littorina littorea (L) and Mytilus edulis (L.). Comp. Biochem. Physiol. 34, 385-397

Pearson, M. P., Burns, M. D, Davies, P. S. (1984). An underwater respirometer and data logger for in situ energy budget studies. J. exp. mar. Biol. Ecol, $74,231-239$

Porter, J. W. (1980). Primary production in the sea reef corals in situ. In: Falkowski, P. G. (ed.) Primary productivity in the sea, Plenum Press, New York, p. 403-410

Precht, H. (1973). The normal temperature range; constant systems. In: Precht, $\mathrm{H}_{\text {, }}$ Christopherson, $\mathrm{J}$. Hensel, $\mathrm{H}_{\text {, }}$ Larcher, W. (ed.) Temperature and life. Springer-Verlag, Berlin, p. $302-354$

Priede, 1. G. (1983). Heart rate telemetry from fish in the natural environment Comp. Biochem. Physiol. 76A: $515-524$

Prosser, C. L. (1973). Comparative animal physiology, 3rd ed. W. B. Saunders, Philadelphia

Rodriguez, G. (1970), Ecological behaviour of some littoral 
caridean decapod crustaceans. Ph. D. thesis, University of Swansea, United Kingdom

Schembri, P. (1979). An unusual respiratory rhythm in the crab Ebalia tuberosa (Pennant) (Crustacea: Decapoda: Leucosiidae), In: Naylor, E., Hartnoll, R. G. (ed.) Cyclic phenomena in marine plants and animals. Pergamon Press, Oxford, p. 327-335

Spaargaren, D. H. (1973). The effect of salinity and temperature on the heart rate of osmoregulating and osmoconforming shrimps. Comp. Biochem. Physiol. 54A: 733-786

Stasko, A. B., Pincock, D. G. (1977). Review of underwater biotelemetry with emphasis on ultrasonic techniques. $\mathrm{J}$. Fish Res. Bd Can. 34:1261-1285

Stevens, E. D. Fry, F. E. J. (1970). Cooling curves of fish. Can. J. Zool. $48: 221-226$

Svoboda, A, (1978), In situ monitoring of oxygen production and respiration in Cnidaria with and without zooxanthellae. In: McLusky, D. S, Berry, A. J. (ed.) Physiology and behaviour of marine organisms. Proceedings of 12 th European Marine Biology Symposium. Pergamon Press, Oxford, p. $75-82$

Taylor, A. C. (1984), Branchial ventilation in the burrowing

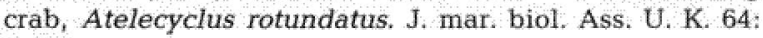
$7-20$

Truchot, J.-P., Duhamel-Jouve, A. (1980). Oxygen and carbon dioxide in the marine intertidal environment diurnal and tidal changes in rockpools. Resp. Physiol. 39: 241-254

Trueman, E. R. (1967). Activity and heart rate of bivalve molluses in their natural habitat. Nature, Lond. 214 : $205-298$

Trueman, E. R. Blatchford, J, G., Jones, H. D, Lowe, G. A. (1973). Recordings of the heart rate and activity of molluscs in their natural habitat. Malacologia 14:377-383

Ulbricht, R. J., Pritchard, A. W. (1972), Effect of temperature on the metabolic rate of sea urchins. Biol, Bull, mar biol. Lab, Woods Hole 142: 178-185 